\title{
Prevalence of and demographic factors associated with domestic violence among Iranian older adults: the results of Urban HEART-2
}

\begin{abstract}
This study aimed to determine the prevalence of and demographic factors associated with domestic violence among Iranian older adults based on the Urban HEART-2 project in Tehran, Iran. The study was a part of the second round of the Urban Health Equity Assessment and Response Tool (Urban HEART-2) project, which was a large, populationbased, cross-sectional study. Individuals aged $\geq 60$ years were selected randomly through a multistage, cluster sampling method from 368 neighborhoods of 22 districts of Tehran. A total of 15,069 older adults, $79 \%$ married and $45.22 \%$ female, were included in the study. The mean age of the par-
\end{abstract}

\begin{abstract}
ticipants was $68.93 \pm 7.27$ years. The overall prevalence of physical domestic violence was $2.32 \%$. Factors such as age, gender, schooling, and having a disability were significantly associated with domestic violence $(p<.05)$. These results are likely to be an underestimate of what really happens in the community, as many authors have mentioned previously. Therefore, it is necessary to broaden our perspectives on the phenomenon of domestic violence against the elderly, especially in the fields of public health and nursing.
\end{abstract}

KEY WORDS

domestic violence; older adults; prevalence; Urban HEART

ORGANIZATION - 1: School of Behavioral Sciences and Mental Health (Tehran Institute of Psychiatry), Iran University of Medical Sciences, Tehran, Iran · 2: Iranian Research Center on Aging, University of Social Welfare and Rehabilitation Sciences, Tehran, Iran · 3: Department of Epidemiology, School of Public Health, Oncopathology Research Center, Iran University of Medical Sciences, Tehran, Iran · 4: Institute of Psychology, Faculty of Social Sciences, University of Gdansk, Poland

AUthors' CONTRIBUtions - A: Study design - B: Data collection - C: Statistical analysis - D: Data interpretation . E: Manuscript preparation · F: Literature search · G: Funds collection

CORRESPONDING AUTHOR - Prof. Vahid Rashedi, School of Behavioral Sciences and Mental Health (Tehran Institute of Psychiatry), Iran University of Medical Sciences, Tehran, Iran, e-mail: rashedi.v@iums.ac.ir; vahidrashedi@yahoo.com to CITE THIS ARTICLE - Rashedi, V., Asadi-Lari, M., Foroughan M., \& Rudnik, A. (2019). Prevalence of and demographic factors associated with domestic violence among Iranian older adults: the results of Urban HEART-2. Health Psychology Report, 7(1), 81-85. https://doi.org/10.5114/hpr.2019.82640 


\section{BACKGROUND}

Domestic violence is a complex and multi-dimensional problem that is defined as each and every act of violence or neglect which harms well-being, physical and psychological integrity, or freedom and the right of a family member and interferes with her/his full development (Reis, Gomes, Reis, Menezes, \& Carneiro, 2014). The World Health Organization (WHO) has defined seven types of violence: physical abuse (defined as the use of physical force); emotional or psychological abuse (defined as the infliction of verbal or nonverbal aggressive acts); neglect (defined as the refusal or failure to fulfill any part of a person's obligations or duties toward an elder); self-neglect (the behavior of an elderly person in a way that threatens his/her own health or safety); abandonment (the desertion of an elderly person by an individual who has assumed responsibility for providing care for him/her); financial or material exploitation (the illegal or improper use of an elder's funds, property, or assets); and sexual abuse (non-consensual sexual contact of any kind with an elderly person) (World Health Organization, 2002b).

The impact of domestic violence on older adults has been less of a focus, and the research into this area is patchy and largely inconclusive (Knight \& Hester, 2016). The WHO states that the prevalence of violence experienced by the elderly varies widely and ranges from $1 \%$ to $35 \%$ (Perel-Levin, 2008). Domestic violence is a problem that manifests itself in both rich and poor countries and at all levels of society (World Health Organization, 2002a). Studies have shown that the prevalence of domestic violence among older adults is $2.20 \%$ in Ireland (Naughton et al., 2011), $5.70 \%$ in Egypt (Abdel Rahman \& El Gaafary, 2012), $12.30 \%$ in Portugal (Gil et al., 2015), and in the range of $13.90 \%$ to $25.80 \%$ among Chinese older adults living in the Greater Chicago area (Dong, Chen, Fulmer, \& Simon, 2014). A systematic review and meta-analysis showed that the overall elder abuse prevalence in Iran was $56.40 \%$ with a $95 \%$ confidence interval of $35.10-75.50 \%$ (Molaei, Etemad, \& Taheri Tanjani, 2017). Many factors are known to be associated with domestic violence, some of which are modifiable. For example, poor and illiterate women and those with low socioeconomic status are at higher risk of domestic violence (Kalokhe et al., 2017).

The increasing incidence of violence against older people is speculated to be a consequence of cultural and social transition processes, changes in social norms and values, and a growing social tolerance for maltreatment of elders (Tobiasz-Adamczyk, Brzyski, \& Brzyska, 2014). Over the last decades, life expectancy has grown in Iran, and currently, over 7.4 million people age 60 years and older, about $9.27 \%$ of the population, live in Iran (Statistical Center of Iran, 2018). Violence against older people remains as a taboo topic in Iran and is still not a well-recognized phenomenon. This study aimed to determine the prevalence of and demographic factors associated with domestic violence among Iranian older adults based on the Urban HEART-2 project in Tehran, Iran.

\section{PARTICIPANTS AND PROCEDURE}

This is a secondary analysis study. The study was a part of the second round of the Urban Health Equity Assessment and Response Tool (Urban HEART-2) project, which was a large population-based cross-sectional study. In this study, individuals aged $\geq 60$ years were selected randomly through a multistage, cluster sampling method from 368 neighborhoods of 22 districts of Tehran, the capital of Iran, in October 2011.

Urban HEART is a user-friendly guide for local and national officials to identify health inequities with the aim of planning actions to reduce them. Using evidence from the WHO's Commission on Social Determinants of Health, Urban HEART encourages policy-makers to develop a holistic approach in tackling health equity. Since the launch of the pilot program in 2008, Urban HEART has been pilot-tested in various cities in Iran, Brazil, Indonesia, Kenya, Malaysia, Mexico, Mongolia, the Philippines, Sri Lanka and Vietnam. By 2011, officials in nearly 50 countries had been trained in using Urban HEART (World Health Organization, 2018). Details of the sampling process in Iran are covered in our previous work (Rashedi et al., 2017; Rashedi, AsadiLari, Foroughan, Delbari, \& Fadayevatan, 2016).

All the participants were interviewed by the interviewers who had been trained during a two-day workshop prior to the data gathering. The aims of the survey were explained to the participants and they were told that they could withdraw from the study at any time during the interview. The data gathering was performed using a standard questionnaire on domestic violence as well as a socio-demographic checklist. The domestic violence questionnaire was developed by experts of the field and its face and content validity was verified by a panel of national experts from various disciplines (Asadi-Lari et al., 2010).

The statistical software SPSS 22.0 (Armonk, NY: IBM Corp.) was used for all the statistical analyses. The descriptive measures were mean, standard deviation, percentages, and frequencies. The chi-square test was used to test associations between variables. The map was created using ArcGIS 10.2.

\section{RESULTS}

A total of 15,069 older adults, 11,899 (79\%) married and $6,805(45.22 \%)$ female, were included in the study. The mean age of the participants was $68.93 \pm 7.27$ years (SE: 0.06). Table 1 presents baseline characteristics of the sample. 
Table 1

Characteristics of participants $(N=15,069)$

\begin{tabular}{|c|c|c|c|}
\hline Variables & $n(\%)$ & Test value $(d f)$ & $p$ \\
\hline Age & & $13.92 x^{2}$ & .009 \\
\hline $60-69$ & $8,848(58.70)$ & & \\
\hline $70-79$ & $4,666(31.00)$ & & \\
\hline $80-89$ & $1,479(9.80)$ & & \\
\hline$\geq 90$ & $76(0.50)$ & & \\
\hline Gender & & $17.62 x^{2}$ & $<.001$ \\
\hline Male & $8,264(54.80)$ & & \\
\hline Female & $6,805(45.20)$ & & \\
\hline Marital status & & $1.55^{x^{2}}$ & .764 \\
\hline Single & $192(1.30)$ & & \\
\hline Married & $11,899(79.00)$ & & \\
\hline Divorced & $143(0.90)$ & & \\
\hline Widow & $2,835(18.80)$ & & \\
\hline Level of education & & $19.11^{x^{2}}$ & .011 \\
\hline Illiterate & $4,069(27.00)$ & & \\
\hline Elementary & $3,198(21.20)$ & & \\
\hline Middle school & $2,353(15.60)$ & & \\
\hline High school & $1,186(7.90)$ & & \\
\hline Diploma & $2,131(14.10)$ & & \\
\hline Academic & $2,132(14.20)$ & & \\
\hline Disability & & $8.15 x^{2}$ & .034 \\
\hline Yes & $1,653(11.00)$ & & \\
\hline No & $13,416(89.00)$ & & \\
\hline
\end{tabular}

The overall prevalence of physical domestic violence was $2.32 \%$ (male $1.33 \%$ and female $0.99 \%$ ). Factors such as age $(p=.009)$, gender $(p<.001)$, level of education $(p=.011)$, and having a disability $(p=.034)$ were significantly associated with domestic violence.

Figure 1 illustrates the prevalence of domestic violence among older adults within all 22 districts of Tehran, categorized in five homogeneous clusters. The prevalence of domestic violence varied very widely among districts, ranging from $0.30 \%$ (districts $1,16)$ to $8.70 \%$ (districts 17 ).

\section{DISCUSSION}

The purpose of the current study was to determine the prevalence of and the demographic factors associated with domestic violence among older adults based on the Urban HEART-2 project in Tehran, Iran. Consis- tent with the findings of Naughton et al. (2011) in Ireland, we found that the overall prevalence of physical domestic violence was $2.32 \%$ (ranging from $0.30 \%$ to $8.70 \%$ ). Information on the prevalence of domestic violence is based on a small number of population-based studies that have been conducted in developed countries. These studies suggest that between $4 \%$ and $6 \%$ of older persons have experienced some form of violence in the home (Wolf, Daichman, \& Bennett, 2002; World Health Organization, 2002b).

In this study, the prevalence of domestic violence was associated with younger age. This finding is in line with the National Violence Against Women Survey (NVAW) in the US, which showed that respondents in the youngest age appeared to be at the greatest risk of experiencing violence (Jasinski \& Dietz, 2004). These lower rates among the older participants of our study may be a function of the true decline in the rates over time or otherwise mere cohort differences.
Prevalence and demographic factors associated with domestic violence 
Vahid Rashedi, Mohsen Asadi-Lari, Mahshid Foroughan, Agata Rudnik

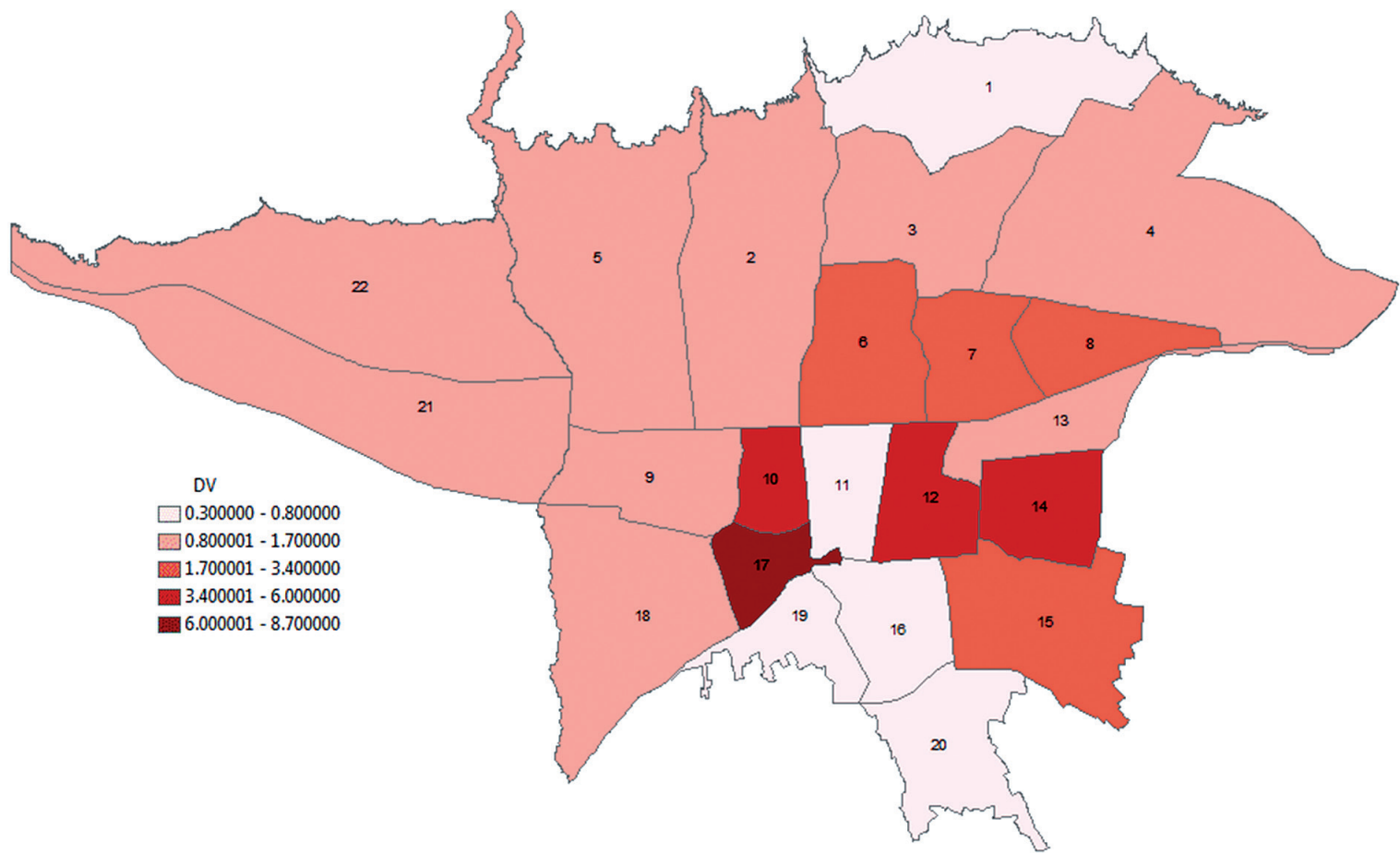

Figure 1. Prevalence of domestic violence within all 22 districts of Tehran.

Many studies have found a higher prevalence of domestic violence in women (Fisher, Zink, Pabst, Regan, \& Rinto, 2003; Giezek et al., 2017; Kilbane \& Spira, 2010; Rode \& Rode, 2017). These findings are inconsistent with the results of the present study. Queiroga Souto et al. in their social phenomenological study found that the victimized older women may ignore their own safety in order to protect the aggressor abuser, and they often have a desire to change the abuser's behavior (Souto, Merighi, Guruge, \& Jesus, 2015).

The result also revealed that a lower level of education was associated with greater risk of domestic violence, and the results were similar to those obtained by Marium in Bangladesh (Marium, 2014) and Özer and Fidrmuc in Turkey (Özer \& Fidrmuc, 2017). Additional years of schooling may alter attitudes toward gender norms and domestic violence by improving their access to information, informing them of their rights, and helping them develop a new sense of selfworth (Erten \& Keskin, 2018). Šmejkalová raised several concerns about domestic violence in the context of the education of seniors, and she suggested the need for primary prevention of domestic violence in the context of the education of older adults at the University of the Third Age (Šmejkalová, 2016).

Our findings indicate that there is a significant relationship between having a disability and domestic violence, which is consistent with the findings of Jasinski and Dietz (Jasinski \& Dietz, 2004). Being affected by several chronic conditions (multi-comorbidity), which characterizes the aging process, very often is associated with impairment and disability, and causes functional dependency in everyday activities (TobiaszAdamczyk et al., 2014). Presumably, older adults with higher levels of disability are more dependent and perhaps are not able to avoid victimization or "leave" a relationship in which they are a victim.

\section{CONCLUSIONS}

These results are likely to be an underestimate of what really happens in the community, as many authors have mentioned previously. Therefore, it is necessary to broaden our perspectives on the phenomenon of domestic violence against the elderly, especially in the fields of public health and nursing. More research to find out about the subtle forms of domestic violence and elder abuse is recommended.

\section{ETHICAL APPROVAL}

Ethical approval was sought from the relevant council in the Municipality of Tehran and the Ethics Committee of Iran University of Medical Sciences (IUMS) in November 2010.

\section{FUNDING}

The Municipality of Tehran funded the main part of the present study. The World Health Organization Centre for Health Development (WHO Kobe Centre) developed the model and supported Urban-HEART in Tehran and more than 60 countries across the world. 


\section{REFERENCES}

Abdel Rahman, T. T., \& El Gaafary, M. M. (2012). Elder mistreatment in a rural area in Egypt. Geriatrics \& Gerontology International, 12, 532-537.

Asadi-Lari, M., Vaez-Mahdavi, M. R., Faghihzadeh, S., Montazeri, A., Farshad, A. A., Kalantari, N., Maher, A., Golmakani, M. M., Salehi, G. H., Motevallian, S. A., \& Malek-Afzali, H. (2010). The application of urban health equity assessment and response tool (Urban HEART) in Tehran concepts and framework. Medical Journal of The Islamic Republic of Iran, 24, 175-185.

Dong, X., Chen, R., Fulmer, T., \& Simon, M. A. (2014). Prevalence and correlates of elder mistreatment in a community-dwelling population of US Chinese older adults. Journal of Aging and Health, 26, 1209-1224.

Erten, B., \& Keskin, P. (2018). For Better or for Worse? Education and the Prevalence of Domestic Violence in Turkey. American Economic Journal: Applied Economics, 10, 64-105.

Fisher, B. S., Zink, T., Pabst, S., Regan, S., \& Rinto, B. (2003). Services and programming for older abused women: The Ohio experience. Journal of Elder Abuse \& Neglect, 15, 67-83.

Giezek, M., Bażydło, M., Ciechowicz, J., Masna, B., Zabielska, P., Tomczak, J., Paszkiewicz, M., Safranow, K., \& Karakiewicz, B. (2017). The results of the "Blue Cards" questionnaire analysis with respect to the incidence of violence among the elderly. Family Medicine \& Primary Care Review, 19, 18-22.

Gil, A. P. M., Kislaya, I., Santos, A. J., Nunes, B., Nicolau, R., \& Fernandes, A. A. (2015). Elder abuse in Portugal: findings from the first national prevalence study. Journal of Elder Abuse \& Neglect, 27, 174-195.

Jasinski, J. L., \& Dietz, T. L. (2004). Domestic violence and stalking among older adults: An assessment of risk markers. Journal of Elder Abuse \& Neglect, 15, 3-18.

Kalokhe, A., del Rio, C., Dunkle, K., Stephenson, R., Metheny, N., Paranjape, A., \& Sahay, S. (2017). Domestic violence against women in India: A systematic review of a decade of quantitative studies. Global Public Health, 12, 498-513.

Kilbane, T., \& Spira, M. (2010). Domestic violence or elder abuse? Why it matters for older women. Families in Society: The Journal of Contemporary Social Services, 91, 165-170.

Knight, L., \& Hester, M. (2016). Domestic violence and mental health in older adults. International Review of Psychiatry, 28, 464-474.

Marium, S. (2014). Women's level of education and its effect on domestic violence in rural Bangladesh. IOSR Journal of Humanities and Social Science, 19, 40-45.

Molaei, M., Etemad, K., \& Taheri Tanjani, P. (2017). Prevalence of Elder Abuse in Iran: A Systematic
Review and Meta Analysis [Research]. Iranian Journal of Ageing, 12, 242-253.

Naughton, C., Drennan, J., Lyons, I., Lafferty, A., Treacy, M., Phelan, A., O’Loughlin, A., \& Delaney, L. (2011). Elder abuse and neglect in Ireland: results from a national prevalence survey. Age and Ageing, 41, 98-103.

Özer, M., \& Fidrmuc, J. (2017). Male education and domestic violence in Turkey: Evidence from a natural experiment. CESifo Working Paper Series, 6526.

Perel-Levin, S. (2008). Discussing screening for elder abuse at primary health care level. Geneva: World Health Organization.

Rashedi, V., Asadi-Lari, M., Delbari, A., Fadayevatan, R., Borhaninejad, V., \& Foroughan, M. (2017). Prevalence of diabetes type 2 in older adults: Findings from a large population-based survey in Tehran, Iran (Urban HEART-2). Diabetes \& Metabolic Syndrome: Clinical Research \& Reviews, 11, 347-350.

Rashedi, V., Asadi-Lari, M., Foroughan, M., Delbari, A., \& Fadayevatan, R. (2016). Prevalence of disability in Iranian older adults in Tehran, Iran: A population-based study. Journal of Health and Social Sciences 1, 251-262.

Reis, L. A. d., Gomes, N. P., Reis, L. A. d., Menezes, T. M. d. O., \& Carneiro, J. B. (2014). Expression of domestic violence against older people. Acta Paulista de Enfermagem, 27, 434-439.

Rode, D., \& Rode, M. M. (2017). Risk factors in committing domestic violence in light of gender psychology. Current Issues in Personality Psychology, 6, 143-153.

Souto, R. Q., Merighi, M. A. B., Guruge, S., \& Jesus, M. C. P. (2015). Older Brazilian women's experience of psychological domestic violence: a social phenomenological study. International Journal for Equity in Health, 14, 44.

Statistical Center of Iran. (2018). Population and housing census. Retrieved from http://www.amar. org.ir/Default.aspx?tabid $=1190$

Šmejkalová, K. (2016). Domestic violence in the context of the education of seniors. Journal of Education Culture and Society, 6, 103-112.

Tobiasz-Adamczyk, B., Brzyski, P., \& Brzyska, M. (2014). Health-related quality of life in older age and a risk of being a victim of domestic violence. Archives of Gerontology and Geriatrics, 58, 388-398.

Wolf, R., Daichman, L., \& Bennett, G. (2002). Abuse of the elderly. In World report on violence and health (pp. 123-145). Geneva: World Health Organization.

World Health Organization (2002a). Active ageing: A policy framework. Geneva: World Health Organization.

World Health Organization (2002b). Missing voices: views of older persons on elder abuse. Geneva: World Health Organization.

World Health Organization (2018). Urban Health Equity Assessment and Response Tool (Urban HEART). Retrieved from http://www.who.int/kobe_centre/ measuring/urbanheart/en/
Prevalence and demographic factors associated with domestic violence 